\title{
Aerial Imaging of Fluorescent Dye in the Near Shore
}

\author{
DAVID B. CLARK \\ Woods Hole Oceanographic Institution, Woods Hole, Massachusetts \\ LUC LENAIN AND FALK FEDDERSEN \\ Scripps Institution of Oceanography, La Jolla, California \\ EMMANUEL BOSS \\ University of Maine, Orono, Maine \\ R. T. GUZA \\ Scripps Institution of Oceanography, La Jolla, California
}

(Manuscript received 1 November 2013, in final form 10 February 2014)

\begin{abstract}
Aerial images are used to quantify the concentration of fluorescent Rhodamine water tracing (WT) dye in turbid and optically deep water. Tracer releases near the shoreline of an ocean beach and near a tidal inlet were observed with a two-band multispectral camera and a pushbroom hyperspectral imager, respectively. The aerial observations are compared with near-surface in situ measurements. The ratio of upwelling radiance near the Rhodamine WT excitation and emission peaks varies linearly with the in situ dye concentrations for concentrations $<20 \mathrm{ppb}\left(r^{2}=0.70\right.$ and $r^{2}=0.85-0.88$ at the beach and inlet, respectively). The linear relationship allows for relative tracer concentration estimates without in situ calibration. The $O(1 \mathrm{~m})$ image pixels resolve complex flow structures on the inner shelf that transport and mix tracer.
\end{abstract}

\section{Introduction}

Fluorescent dye tracers (Fig. 1) are used to study dispersion and transport in many aqueous environments (Pritchard and Carpenter 1960; Csanady 1963; Okubo 1971; Fong and Stacey 2003; Clark et al. 2010; and others). Dye tracer sources are known, and diffusivity estimates are improved relative to many natural tracers. Fluorescent dyes are accurately measured in situ with optical fluorometers, even in the surfzone with high concentrations of optical scatterers (Clark et al. 2009). Nearshore dye sampling with hand-filled bottles (e.g., Harris et al. 1963) has been improved upon with continuous in situ sampling techniques, which result in dye concentration transects or single-location time series (Fong and Stacey 2003; Clark et al. 2010). These

Corresponding author address: David Clark, Woods Hole Oceanographic Institution, MS\#12, 266 Woods Hole Rd., Woods Hole, MA 02543.

E-mail: dclark@whoi.edu techniques provide high-quality tracer concentration measurements, but the spatial coverage is limited and, in general, complex eddy stirring structures cannot be identified.

Remote sensing of dye tracers provides greater spatial coverage than in situ sampling. Laser stimulated fluorescence using a bathymetric lidar system has been used to create three-dimensional maps of tracer concentration in clear open-ocean waters (Sundermeyer et al. 2007). However, lidar measurements are costly and complex, and few fluorescent dye studies have been conducted in turbid nearshore waters.

Passive aerial imaging of solar stimulated fluorescence offers a relatively simple, low-cost method for studying tracer dispersion, albeit without resolving vertical structure. In relatively clear open ocean (case 1) waters, dye fluorescence has been studied using combined upwelling and downwelling radiance, and a two-flow model for absorption, backscatter, and fluorescence (Spitzer and Wernand 1983). Aerial imaging has also been used in qualitative studies of tracer dispersion in the near shore 

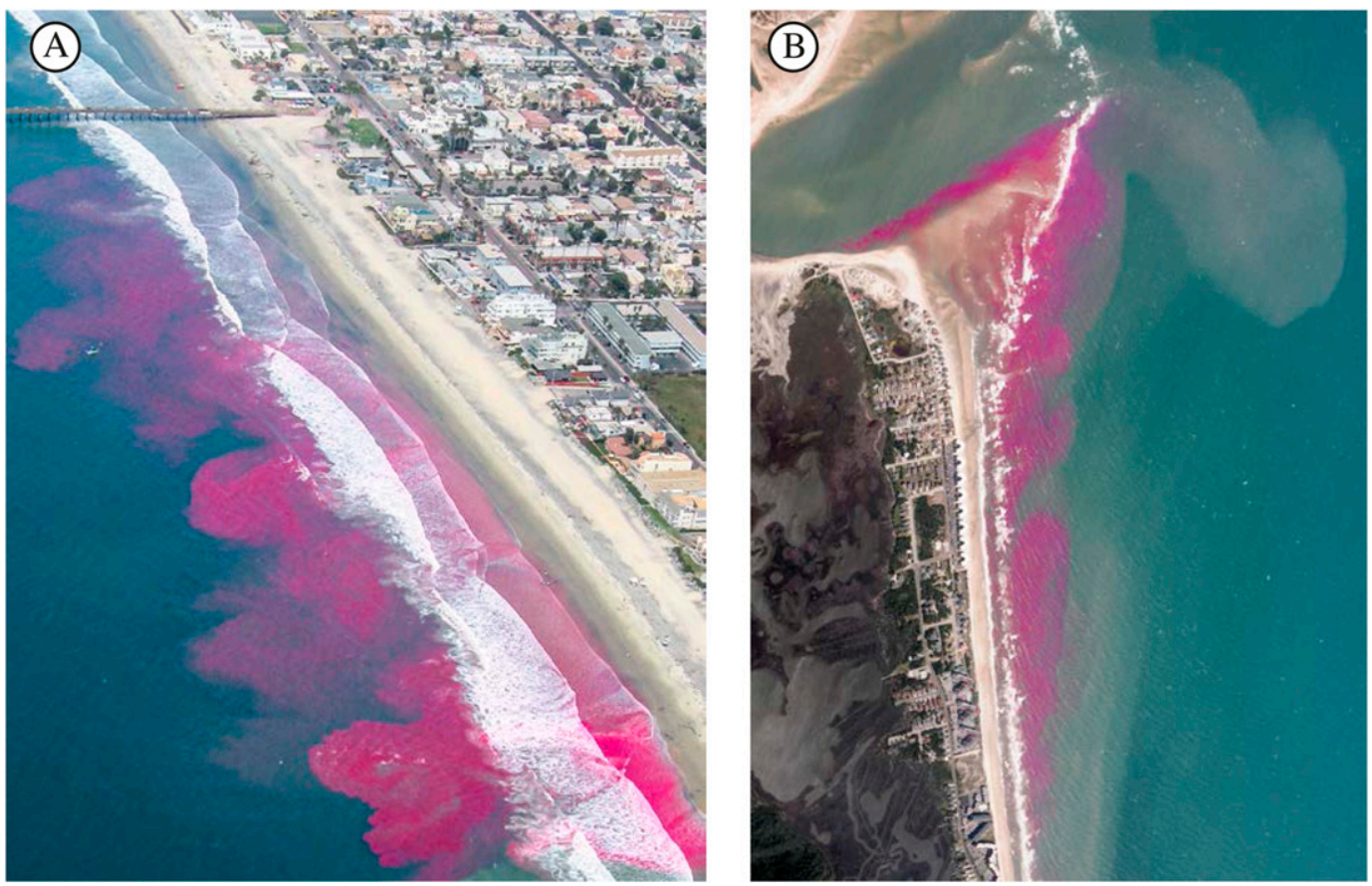

FIG. 1. Color-enhanced photographs of dye tracer released (a) within the surfzone at Imperial Beach, California, and (b) within an ebb tidal flow at New River Inlet, North Carolina. The structure of tracer ejected seaward of the surfzone is not resolved by sampling transects using jet ski and boat.

(Grant et al. 2005) and for eddy diffusivity estimates on the inner shelf (Bogucki et al. 2005). However, remote sensing methods for measuring tracer concentrations in turbid coastal waters (case 2 waters) with the spatial resolution necessary to resolve small-scale $(\sim 10 \mathrm{~m})$ structures (e.g., Fig. 1) in the nearshore zone have not been described.

Here we develop simple airborne-based optical methods for measuring near-surface fluorescent Rhodamine water tracing (WT) dye in the nearshore region (within several hundred meters of the shoreline) by empirically calibrating to in situ dye observations. Fluoresced light and excitation illumination are both exponentially attenuated, resulting in a surface-weighted dye signal with a vertical $e$-folding scale of $<2 \mathrm{~m}$ (based on pure water; Pope and Fry 1997). The study is conducted in optically deep waters (i.e., the bottom does not contribute to the signal), and where the mean optical pathlength is smaller than the vertical scales of tracer variation (i.e., the aerial dye concentration estimate is comparable with a near-surface in situ estimate). The goal is to generate spatial maps of near-surface dye concentration that are appropriate for studying transport and dispersion on relatively small $O(10-100 \mathrm{~m})$ scales, and to do so without the use of radiative transfer models or complex optical transformations.
In section 2 two aerial imaging systems are described, one deployed near an exposed ocean beach [Imperial Beach 2009 (IB09) experiment] and the other used near a tidally flushed inlet [River Mouth and Inlet (RIVET) experiment]. The aerial and in situ data are compared and measurement errors estimated for the two imaging systems in sections 3 (IB09) and 4 (RIVET). Aerial measurements and their potential uses are discussed in section 5 , and section 6 is a summary.

\section{Instrumentation and methods}

Multispectral and hyperspectral imagery were recorded during the IB09 (section 3) and RIVET (section 4) experiments using the Modular Aerial Sensing System (MASS) developed by Ken Melville's Air-Sea Interaction Research Laboratory (http://airsea.ucsd.edu), at Scripps Institution of Oceanography. The system is modular, rapidly deployable, lightweight, and platform independent. It typically includes a scanning waveform lidar (Riegl Q680i), tightly coupled GPS/inertial navigation system (INS) devices (Novatel SPAN-LN200 and OXTS RT3003), a longwave IR camera (FLIR SC6000HS), and a set of multispectral camera systems. For the dye experiments, the MASS was set up with multispectral cameras (IB09) and a hyperspectral imager (RIVET). 


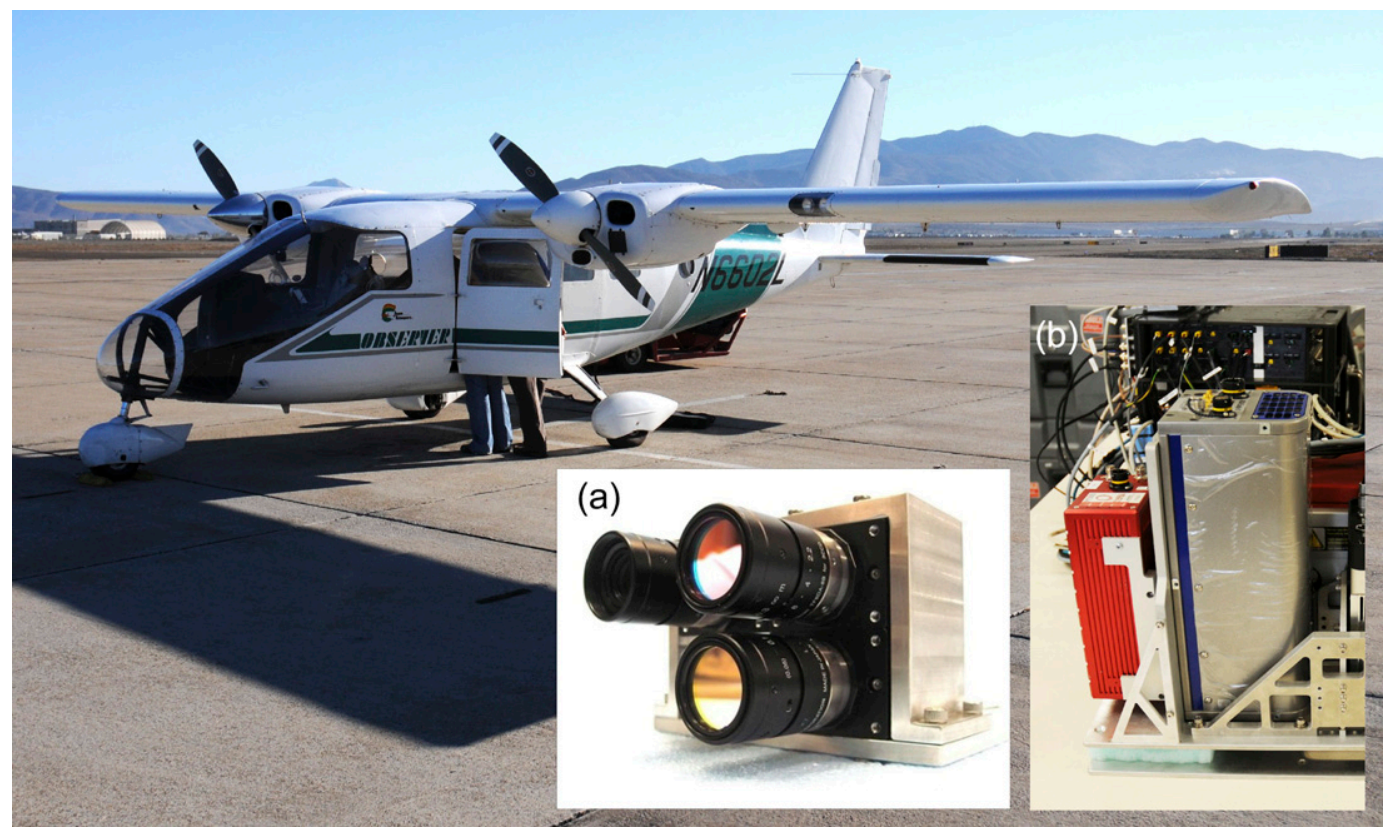

FIG. 2. Partenavia P68 Observer aircraft used during both experiments. (a) Multispectral dye fluorescence camera system used during IB09 and (b) hyperspectral pushbroom visible-to-NIR imager used during RIVET.

\section{a. Multispectral dye fluorescence camera}

During IB09, a preliminary version of the MASS included a multispectral camera system, and a Coda Octopus F180 plus dual-antenna L1/L2-capable GPS/INS that provided aircraft position and attitude information. Low-profile antennas were installed on the fuselage of the aircraft, aft of the forward part of the wing with a baseline (distance between the two antennas) of $2 \mathrm{~m}$ in the Partenavia P68 Observer aircraft used during the deployment (Fig. 2). A 24-state Kalman filter routine processes the GPS/INS data to provide position and attitude (roll, pitch, heading) information at $100 \mathrm{~Hz}$. NovAtel Waypoint GrafNav is used to calculate differential GPS trajectories, leading to a horizontal position accuracy of $0.02 \mathrm{~m}$, and attitude accuracies of $0.03^{\circ}$, $0.03^{\circ}$, and $0.1^{\circ}$ for roll, pitch, and heading, respectively. Multispectral video was captured by two monochrome digital video cameras (Prosilica GC1290). The focal length of both cameras was $8 \mathrm{~mm}$, and the focus was set to infinity. Sensor integration times were adjusted independently on both cameras to maximize the signal-tonoise ratio (SNR) while minimizing sun glitter, and ranged from 1 to $3 \mathrm{~ms}$. The images were normalized for integration time in postprocessing. The camera captured 1 megapixel $(1280 \times 960), 12$-bit images at five frames per second (fps), which were streamed to a personal computer (PC) through Institute of Electrical and Electronics Engineers (IEEE) 802.3 1000baseT network communication, and recorded to a local drive using IO
Industries Streams5 software. The cameras were synchronized and triggered by a National Instruments NI-6251-USB data acquisition board, slaved to a single pulse per second provided by one of the GPS receivers on the GPS/INS. The two monochrome camera lenses are outfitted with bandpass filters from 530 to $560 \mathrm{~nm}$ and from 590 to $620 \mathrm{~nm}$ to capture wavelengths near the excitation and emission peaks of the Rhodamine WT dye. Both cameras were mounted pointing to the same field of view (FOV) $25^{\circ}$ forward from nadir, thus minimizing direct sun glitter when flying away from the sun. Lens distortion (Holland et al. 1997) is accounted for with calibrations using a black-and-white checkerboard pattern to calculate the intrinsic lens parameters (Bouguet 2013). The camera location and orientation is calculated for each image using GPS/INS data that are linearly interpolated to the camera acquisition time. To remove the aircraft motion from the sequence of images, each pixel is reprojected in an Earth coordinate frame following Kleiss (2009).

\section{b. MASS hyperspectral imager}

During the RIVET experiment, near-surface dye was imaged using the SIO MASS nadir-looking hyperspectral imager installed on a Partenavia P68 Observer. The imager is a pushbroom hyperspectral system (SPECIM AisaEAGLE) in the 400-970-nm range (visible and near infrared) with $1.25-\mathrm{nm}$ native spectral resolution. The FOV is $37.7^{\circ}$ with 944 spatial pixels. Integration 
time was adjusted during flights to improve SNR, usually ranging between 5 and $10 \mathrm{~ms}$, and the camera repetition rate was set to $80 \mathrm{fps}$. The spectral resolution at each pixel was reduced to $5 \mathrm{~nm}$ to improve SNR. Incoming downwelling radiation is measured using a fiber optic downwelling irradiance sensor (FODIS), synchronized with the hyperpectral camera.

The camera was calibrated at the SpecTIR facility (Reno, Nevada) prior to the flights. The resulting calibration provides data that are within $\pm 5 \%$ of absolute radiance with central wavelength locations within $0.5-\mathrm{nm}$ accuracy. Noise level is measured at the end of each flight line by closing the lens using an electromechanical shutter. The noise reference value is removed from the imagery prior to radiance calibration. The radiometric calibration and measured incoming downwelling radiance is then applied to convert the raw data values to radiance units $\left[\mathrm{mW}\left(\mathrm{cm}^{2} \mathrm{sr} \mu \mathrm{m}\right)^{-1}\right.$ ].

A Novatel Synchronous Position, Attitude, and Navigation (SPAN)-LN200 GPS/INS sampling at $200 \mathrm{~Hz}$ provides position and attitude information, required for reprojecting each pixel in an Earth coordinate frame (Kleiss 2009). After differential GPS processing using Waypoint Inertial Explorer software, we obtain $0.01 \mathrm{~m}$ $(0.015 \mathrm{~m})$ horizontal (vertical) accuracies, and attitude accuracies of $0.005^{\circ}, 0.005^{\circ}$, and $0.008^{\circ}$ for roll, pitch, and heading, respectively.

\section{c. Jet ski-based in situ dye sampler}

In situ surface dye measurements were acquired with two jet ski-based dye sampling platforms that allow dye concentration measurements on cross- and alongshore transects in the near shore and through breaking waves in the surfzone (Clark et al. 2009). Water pumped from $20 \mathrm{~cm}$ below the surface passes through a temperature sensor, a debubbler, a flow rate sensor, a Turner Designs Cyclops turbidity sensor, and a WetLabs WETStar Rhodamine WT fluorometer. Errors in in situ tracer concentration are $<5 \%$ of the dye concentration magnitude. Contaminated jet ski observations are discarded (e.g., when the jet ski is traveling $>8 \mathrm{~m} \mathrm{~s}^{-1}$, turning, jumping, or sampling within the foamy face of a breaking wave). Jet ski data are also removed when the jet ski turbidity was elevated more than $20 \%$ above background levels, or if the pump flow rate was reduced by more than $10 \%$.

\section{d. Rhodamine WT optics}

Example spectra from the RIVET experiment show the effect of dye on the measured upwelling radiance (Fig. 3). The radiance for water without dye is nearly constant from 450 to $580 \mathrm{~nm}$ and decreases at longer wavelengths. For water containing dye, there is a measured

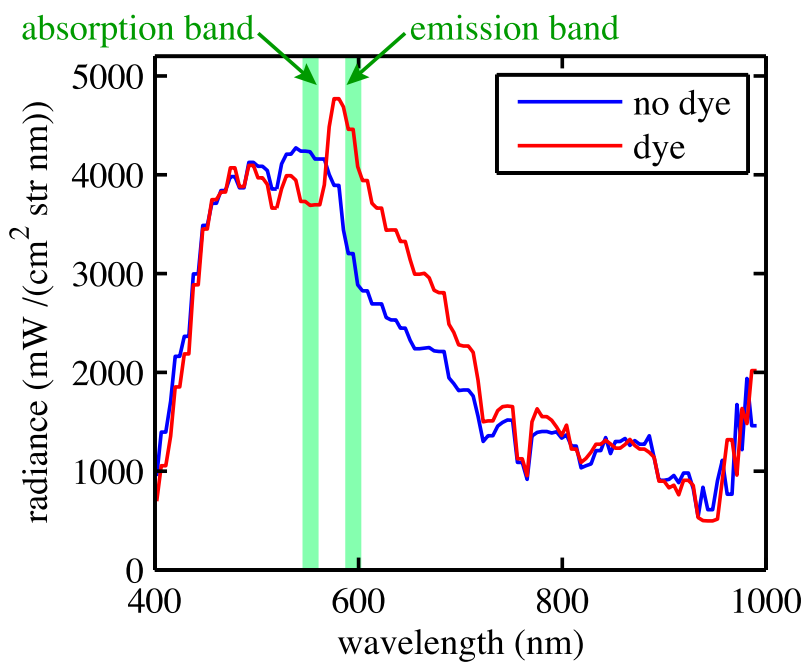

FIG. 3. Radiance vs wavelength for regions with (red curve) and without (blue curve) dye, measured by the hyperspectral imager at New River Inlet. Light green vertical bars indicate the wavelengths used by the hyperspectral system to measure dye. The multispectral system uses similar wavelengths (not shown) with larger bandpass widths.

decrease in radiance (dye excitation) between 530 and $570 \mathrm{~nm}$ and an increase in radiance (dye emission) between 570 and $750 \mathrm{~nm}$ (Fig. 3), with the maximum changes in radiance due to dye excitation and emission near 553 and $595 \mathrm{~nm}$, respectively. The maximum changes in radiance occur at shorter (excitation) and longer (emission) wavelengths than the 557- and 582-nm peaks in the excitation and emission spectra of Rhodamine WT (Viriot and Andre 1989), respectively, and the differences likely result from the overlap in excitation and emission spectra near $570 \mathrm{~nm}$.

The ratio of the mean radiances in the emission $\left(\bar{L}_{\mathrm{em}}\right)$ and excitation $\left(\bar{L}_{\mathrm{ex}}\right)$ bands

$$
R=\frac{\bar{L}_{\mathrm{em}}}{\bar{L}_{\mathrm{ex}}}
$$

is used to estimate dye concentration. The $\bar{L}_{\mathrm{ex}}$ and $\bar{L}_{\mathrm{em}}$ are the bandpass-averaged radiances measured from 546 to $560 \mathrm{~nm}$ and from 588 to $602 \mathrm{~nm}$ for the hyperspectral system, respectively, while the multispectral system uses uncalibrated pixel brightness over 530-560 and $590-620 \mathrm{~nm}$. The ratio $R$ exploits the dye-induced changes in the $\bar{L}_{\mathrm{ex}}$ and $\bar{L}_{\mathrm{em}}$ bands to create a metric that is sensitive to dye concentration, while normalizing for changes in incident light intensity.

The ratio $R$ is expected to be roughly linear in dye concentration $D$, for low $D$, and to be increasingly nonlinear for high $D$ (see appendix). At high $D$ the effect of the nonlinearity (convex or concave) is determined by 
TABLE 1. IB09 aerial flight and dye release information. Dye was released in the surfzone, in 1-m water depth, with dye continuously injected at $0.5 \mathrm{~m}$ above the bed (continuous release) or poured into the surface (patch release).

\begin{tabular}{|c|c|c|c|c|c|c|c|}
\hline Day & $\begin{array}{c}\text { No. of aerial } \\
\text { passes }\end{array}$ & $\begin{array}{l}\text { Pass time } \\
\text { range }(\mathrm{s})\end{array}$ & $\begin{array}{l}\text { Altitude } \\
\text { range }(\mathrm{m})\end{array}$ & $\begin{array}{l}\text { Image mosaic } \\
\text { resolution }(\mathrm{m})\end{array}$ & $\begin{array}{c}\text { Dye release } \\
\text { type }\end{array}$ & $\begin{array}{c}\text { Release } \\
\text { duration (min) }\end{array}$ & $\begin{array}{c}\text { Release } \\
\text { volume }(\mathrm{L})\end{array}$ \\
\hline 13 Oct & 12 & $70-120$ & $550-670$ & 2 & Continuous & 392 & 55 \\
\hline 14 Oct & 20 & 90-130 & $370-670$ & 2 & Patch & - & 20 \\
\hline 15 Oct & 25 & $40-70$ & $640-760$ & 2 & Patch & - & 15 \\
\hline 16 Oct & 4 & $50-70$ & 610 & 2 & Continuous & 395 & 55 \\
\hline
\end{tabular}

the water absorption and backscattering coefficients when dye is not present.

\section{e. Rhodamine WT temperature dependence}

The fluorescence of Rhodamine WT is temperature dependent (Smart and Laidlaw 1977) with the form

$$
D_{T_{0}}=D_{T} e^{0.027\left(T-T_{0}\right)}
$$

where $D_{T_{0}}$ is the dye at the calibration temperature $T_{0}$ and $D_{T}$ is the field measurement at temperature $T$. In situ measurements are temperature corrected to get dye concentrations in parts per billion (ppb). The aerial calibrations presented in sections 3 and 4 have mean near-surface water temperatures of $T_{0}=18.5^{\circ} \mathrm{C}$ for IB09 and $T_{0}=23^{\circ} \mathrm{C}$ for RIVET, and (2) should be used when applied to other systems. Temperature variations $\left( \pm 1^{\circ} \mathrm{C}\right)$ during each field experiment are not accounted for in aerial estimates and add errors of $\pm 3 \%$ to the dye concentration magnitudes. Simultaneous thermal imaging (not used here) could be used to correct dye estimates in an environment with large temperature variations.

\section{Multispectral camera dye observations, IB09}

IB09 was conducted at Imperial Beach, California, in September-October 2009 (Feddersen 2012; Rippy et al. 2013). Imperial Beach is an exposed ocean beach, with roughly alongshore homogenous bathymetry in shallow water $(<4-\mathrm{m}$ depth). Combined aerial and in situ sampling of dye was conducted on 4 days (Table 1 ). The in situ observations were acquired with two jet ski-based sampling platforms (section 2c) within $500 \mathrm{~m}$ of the shoreline. The sky was mostly clear, with minimal interference from clouds. Vertical casts of in situ dye concentration found the dye to be well mixed over the top $3 \mathrm{~m}$ of the water column.

The multispectral camera acquired 45-57 passes over the dye field for each release, and the number of passes with coincident in situ data ranges from 4 to 25 (Table 1 ). The georeferenced images from each pass are regridded onto a rectangular $2 \mathrm{~m} \times 2 \mathrm{~m}$ grid. Each grid element is imaged 35-40 times over the 7-8-s duration the location is in the FOV. The time stack of pixel brightness at a given location contains many views of the water surface, some of which are clear, while others contain breaking waves or intense surface reflections. Sun glitter and the white foam from breaking waves are reduced by using the minimum pixel brightness value in each pixel time stack, and the minimum value mosaic is used to estimate dye concentrations. The remaining white foam from breaking waves is removed by discarding pixels where the excitation image brightness is above an empirical threshold, chosen to be the maximum value that still eliminates breaking waves.

In situ dye concentration measurements and aerial image pixels acquired close in time and space are compared (Fig. 4b). For each in situ data point collected during an aerial pass (1-2 min in duration), the nearest pixel within $5 \mathrm{~m}$ is used for comparison. The jet ski wakes are removed by discarding any pixels with brightness over an empirically chosen threshold, similar to breaking waves.

The ratio $R$ (1) is linearly fit to the in situ dye concentrations $D=\alpha R+\beta$, where $\alpha$ and $\beta$ are constants. Many other fits were explored, including higher-order polynomials and logarithmic functions; however, the improvements in fit $r^{2}$ were not significant. The best-fit multispectral dye concentration estimate $\mathcal{D}_{M}$ is

$$
\mathcal{D}_{M}=17.25 R-8.39
$$

with $r^{2}=0.70$, and where the errors ( $95 \%$ confidence) in the fit constants are $<0.2$. When applying (3) to water with a different temperature, it should be multiplied by (2) with $T_{0}=18.5^{\circ} \mathrm{C}$.

The aerial and in situ dye concentration estimates have a roughly linear relationship below $20 \mathrm{ppb}$, with aerial estimates underpredicting the in situ estimates above $20 \mathrm{ppb}$ (Fig. 4a). The aerial dye estimate errors below $20 \mathrm{ppb}$ are a combination of scatter (error bars in Fig. 4a) and the weak nonlinearity. The standard deviation of the aerial estimate ranges from $\pm 1.5 \mathrm{ppb}$ near $D=0$ to $\pm 4.5 \mathrm{ppb}$ near $D=20 \mathrm{ppb}$, and the bias ranges from +1.7 near $D=9$ ppb to -2.5 near $D=20$ ppb. For in situ $D>20 \mathrm{ppb}$, the aerial dye estimate is increasingly 

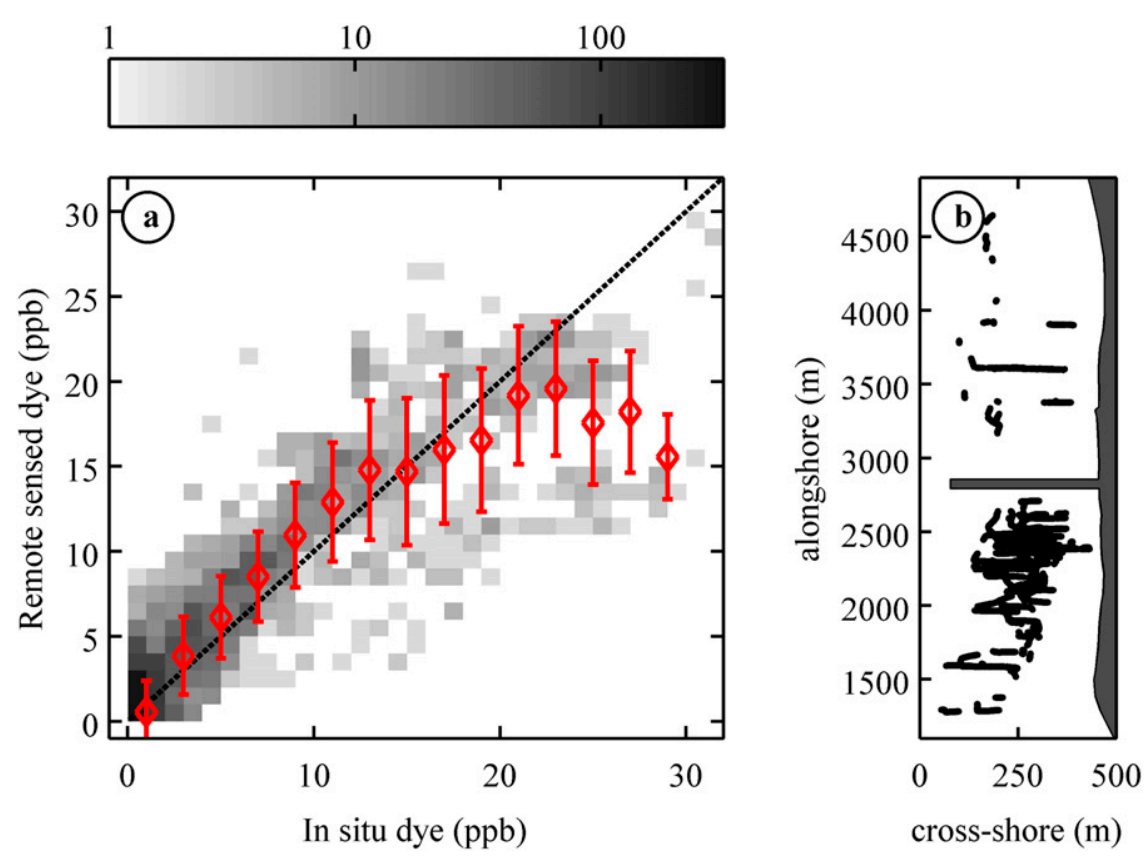

FIG. 4. (a) Multispectral dye estimate (3) vs in situ-measured dye concentration during IB09, shown as binned means plus or minus one standard deviation (red curve) and the number of samples (logarithmic gray background; see legend). All data points are used in fitting (3). (b) Locations of collocated in situ and multispectral data used for comparison in (a), with dark gray regions indicating land and the Imperial Beach pier.

biased low, and is most likely due to the nonlinearity of $R$ at high dye concentrations (see appendix). However, statistics at very high concentration $(D>25 \mathrm{ppb})$ are poor (few samples) and the nonlinearity is not well resolved.

The aerial dye concentrations contain errors due to variations in the relationship between $D$ and $R$, in situ dye measurement errors, variation in $D$ (assumed to be small) over a typical optical path, temperature variations (section 2e), and spatial errors in matching aerial and in situ data. Large errors in aerial dye concentration estimates result from small spatial errors near sharp dye concentration fronts (typical in the near shore). Thus, the dye estimate errors presented here (Fig. 4a) are an upper bound, and improvements may be made using more accurate spatial data.

The potential of this method to reveal quantitative new information about rip current-driven exchange between the surfzone and inner shelf is demonstrated with a series of multispectral-estimated dye mosiac images for $t=90,124$, and $278 \mathrm{~min}$ after a continuous dye release on 13 October 2009 (Fig. 5). The alongshore current transports surfzone dye upcoast, while sporadic rip currents eject dye offshore. Near the release location, rip currents create $\approx 50$-m-wide filaments of concentrated dye about $150 \mathrm{~m}$ offshore of the outer edge of the surfzone (Figs. 5a,b). Farther upcoast from the dye source, the ejected dye field is more diluted and is less patchy (Fig. 5c), perhaps as the result of many rip current events blending together. This method provides quantitative data to study rip current-driven exchange processes.

\section{Hyperspectral dye fluorescence imaging, RIVET}

The RIVET experiment took place during May 2012 at New River Inlet, North Carolina. The tidal inlet mouth is roughly $1 \mathrm{~km}$ wide, has tidal currents of $\pm 1 \mathrm{~m} \mathrm{~s}^{-1}$, with an ebb shoal that extends $500 \mathrm{~m}$ seaward of the mouth, and sandy beaches to the northeast and southwest (Fig. 1b). Dye was released on 4 days and observed with aerial hyperspectral and in situ instrumentation (summarized in Table 2). Dye released within the inlet during ebb tidal flows was advected seaward into the ocean. Vertical casts of in situ dye concentration found the dye was well mixed over the top 2-4 $\mathrm{m}$ of the water column.

Surface dye concentration was measured using the same two jet ski-based dye measuring systems used during IB09 (section 2c). Each jet ski sampled from 2 to $4 \mathrm{~h}$ during and after completion of the dye release, from within the inlet to $2400 \mathrm{~m}$ offshore, and up to $6000 \mathrm{~m}$ alongshore from the inlet mouth (Fig. 6). Hyperspectral observations generally were acquired on alongshore 
$\mathrm{T}=90 \mathrm{~min}$

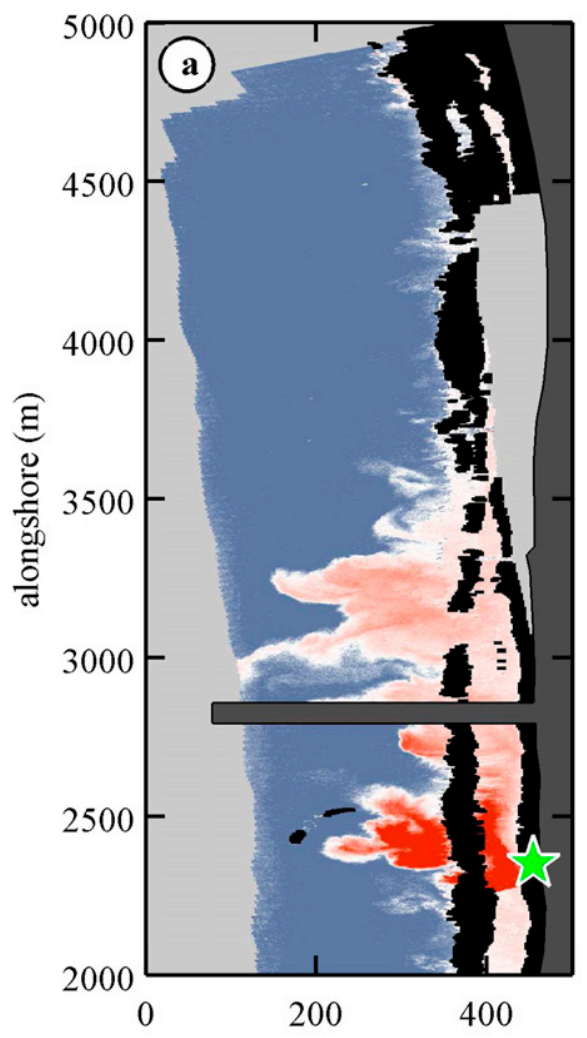

$\mathrm{T}=124 \mathrm{~min}$

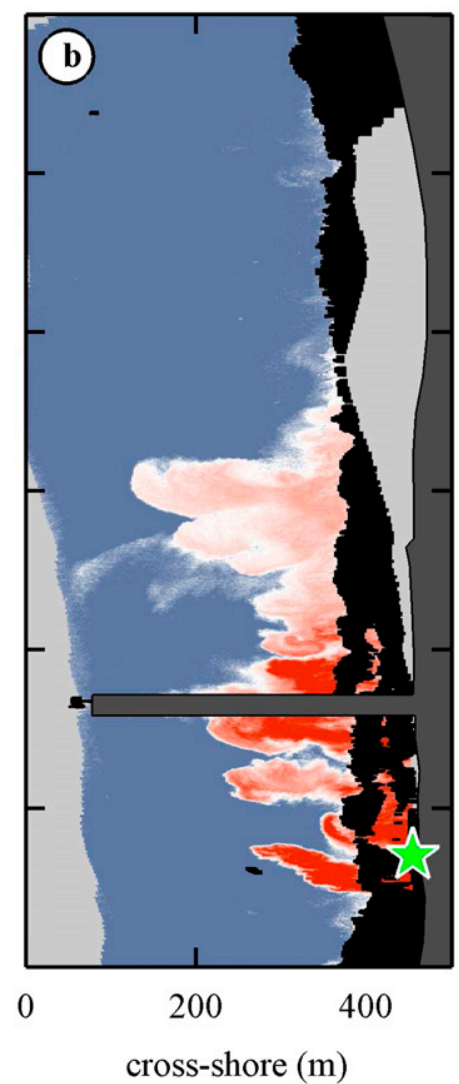

$\mathrm{T}=278 \mathrm{~min}$

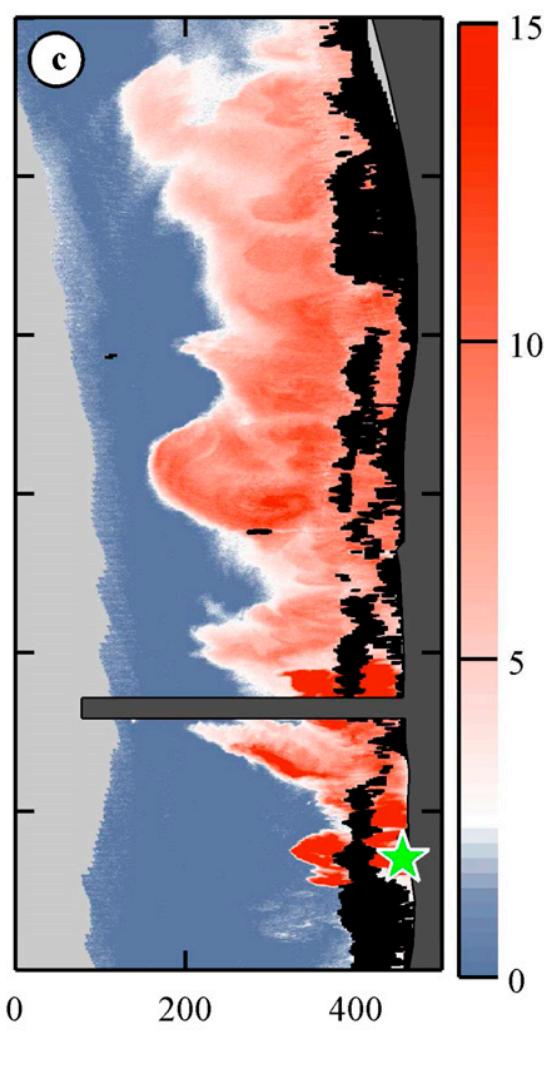

FIG. 5. Dye concentrations (ppb, see color bar) at 3 times after the start of a continuous release on 13 Oct during IB09. The green star indicates the dye release location. Dark gray regions indicate land and the Imperial Beach pier, light gray regions indicate water outside the imaged area, and black regions indicate foam from breaking waves.

flight paths with swath widths ranging from 500 to $1500 \mathrm{~m}$. The number of passes, pass durations, flight altitudes, and along-track resolutions are given in Table 2.

For each in situ data point collected during an aerial pass (typically $1-3 \mathrm{~min}$ in duration; see Table 2), the nearest pixel within $5 \mathrm{~m}$ is used for comparison. The resulting $R(1)$ and $D$ vector pairs are combined for all 4 days (Fig. 6). Hyperspectral/in situ comparison is limited to the region near and offshore of the inlet mouth. Observations more than $200 \mathrm{~m}$ inland from the inlet mouth are not included.

The hyperspectral radiance ratios $R(1)$ are linearly fit to the in situ dye concentrations $D$. The hyperspectral dye concentration estimate $\mathcal{D}_{H}$ is

$$
\mathcal{D}_{H}=14.2 R-10.7
$$

where the errors ( $95 \%$ confidence) in the fit constants are $<0.05$. The aerial and in situ dye estimates are similar (Fig. 7a), with $r^{2}=0.85$. The relationship between in situ and aerial concentrations is roughly linear, with a decrease in aerial estimates for $D>20 \mathrm{ppb}$. The standard deviation of the binned aerial estimate $\mathcal{D}_{H}$ increases with $D$ (vertical bars, Fig. 7a), and ranges from \pm 0.8 ppb near $D=0$ ppb to \pm 4.0 ppb near $D=$ $20 \mathrm{ppb}$, and the bias of $\mathcal{D}_{H}$ varied from +0.5 near $D=5 \mathrm{ppb}$ to -2.5 near $D=20 \mathrm{ppb}$. When applying (4) to water with a different temperature, it should be multiplied by (2) with $T_{0}=23^{\circ} \mathrm{C}$.

The fit constants in (4) are dependent on the ratio $R_{\mathrm{NIR}}=\bar{L}_{\mathrm{NIR}} / \bar{L}_{\mathrm{BG}}$, defined similar to (1), where $\bar{L}_{\mathrm{NIR}}$ is the mean upwelling radiance in the near-infrared (NIR) band (800-900 nm) and $\bar{L}_{\mathrm{BG}}$ is the mean upwelling radiance in the blue-green $(475-510 \mathrm{~nm})$ band. These bands are outside the excitation and emission peaks of Rhodamine WT (the correlation of $R$ and $R_{\mathrm{NIR}}$ is near zero), and in the RIVET dataset $R_{\mathrm{NIR}}$ depends primarily on the background ocean color. Data falling far below the one-to-one line in Fig. $7 \mathrm{a}$, where the $\mathcal{D}_{H}$ underpredicts the in situ measurement, is characterized by high $R_{\mathrm{NIR}}$. In the RIVET dataset, $R_{\mathrm{NIR}}$ ranged from 0.11 to 0.30 , with outliers ranging from 0.09 to 0.50 . 
TABLE 2. RIVET aerial flight and dye release information. Dye was released continuously at $650 \mathrm{~m}$ inside the inlet mouth, or released as patches 2700-3000 m "upstream" from the inlet mouth. During continuous releases dye was pumped through a small diffuser located $5 \mathrm{~m}$ above the bed in 10-m water depth, while patch releases were poured directly into the water surface in 4-m water depth.

\begin{tabular}{|c|c|c|c|c|c|c|c|}
\hline Day & $\begin{array}{c}\text { No. of aerial } \\
\text { passes }\end{array}$ & $\begin{array}{l}\text { Pass time } \\
\text { range }(\mathrm{s})\end{array}$ & $\begin{array}{l}\text { Altitude } \\
\text { range }(m)\end{array}$ & $\begin{array}{l}\text { Pixel spacing } \\
\text { (m) }\end{array}$ & $\begin{array}{c}\text { Dye release } \\
\text { type }\end{array}$ & $\begin{array}{c}\text { Release } \\
\text { duration }(\min )\end{array}$ & $\begin{array}{c}\text { Release } \\
\text { volume (L) }\end{array}$ \\
\hline 7 May & 47 & $50-250$ & 799-1800 & $\leq 1.6$ & Continuous & 139 & 112 \\
\hline 8 May & 47 & $40-140$ & $1200-2200$ & $\leq 1.9$ & Continuous & 145 & 104 \\
\hline 11 May & 45 & $50-180$ & $1200-2500$ & $\leq 2.2$ & Patch & - & 76 \\
\hline 12 May & 45 & $50-180$ & $1000-2200$ & $\leq 1.9$ & Patch & - & 76 \\
\hline
\end{tabular}

A four-band hyperspectral dye estimate $\mathcal{D}_{\mathrm{H} 4}$ similar to (4) but including fit coefficients that are dependent on $R_{\mathrm{NIR}}$ is

$\mathcal{D}_{\mathrm{H} 4}=\left(42.3 R_{\mathrm{NIR}}+6.1\right) R+\left(-39.8 R_{\mathrm{NIR}}-3.3\right)$.

The aerial $\mathcal{D}_{\mathrm{H} 4}$ and in situ $D$ are similar, with $r^{2}=0.88$ (Fig. 7b). The standard deviations of the binned $\mathcal{D}_{\mathrm{H} 4}$ are slightly smaller than those for $\mathcal{D}_{H}$, and range from \pm 0.7 ppb near $D=0 \mathrm{ppb}$ to $\pm 3.0 \mathrm{ppb}$ near $D=20 \mathrm{ppb}$, while the bias of $\mathcal{D}_{\mathrm{H} 4}$ is nearly identical to that for $\mathcal{D}_{H}$ (Fig. $7 \mathrm{~b})$. The $R_{\mathrm{NIR}}$-dependent "slope" of (5) (the terms multiplying $R$ ) ranges from 12 to 16 for the majority of the data, with outliers near 10 and 30 . The $R_{\mathrm{NIR}^{-}}$ dependent "intercept" [second set of brackets in (5)] ranges from -13 to -9 with outliers near -22 and -7 . When applying (5) to water with a different temperature, it should be multiplied by (2) with $T_{0}=23^{\circ} \mathrm{C}$.

Dye concentration maps are generated for each aerial pass using (4), and examples are given for $t=74,131$, and $237 \mathrm{~min}$ after the continuous dye release began on 7 May (Fig. 8). A high-concentration stream of dye flows out of the inlet along the inlet's southern edge, with dye advected south along the outer edge of the ebb shoal and following the shoreline to the south (Figs. 8a,b). In the region to the south of the inlet, dye is rapidly transported south within the surfzone, while dye is ejected from the surfzone in billow-shaped structures (Figs. 8a,b). After $237 \mathrm{~min}$ (98 $\mathrm{min}$ after the dye release stopped), the rapid transport within the surfzone has advected clear water into the region along the shoreline just south of the inlet while dye remains farther offshore (Fig. 8c). At the seaward edge of the surfzone, the dye field shows evidence of shear instabilities, with dye being transported from offshore back into the surfzone (Fig. 8c).

\section{Discussion}

The multispectral camera equipment is relatively low cost, with the INS being the most expensive component. Dye concentration estimates could be performed without the INS, using ground control points to rectify and georeference the images, and reducing the cost of the system to two cameras and a laptop computer. Georeferencing using ground control points is possible if a number of stationary objects with known positions are present in the images, but it would not be appropriate for images containing only the water surface. This method might result in greater spatial errors in the location of each pixel; however, the dye concentration estimate would not be degraded. A slight distortion of the measured dye patch is not likely to hinder the identification of mixing structures (eddies, jets, etc.) in the dye field, and it does not pose significant problems for the estimation of dye moments if the spatial errors are much smaller than the scale of the dye patch.

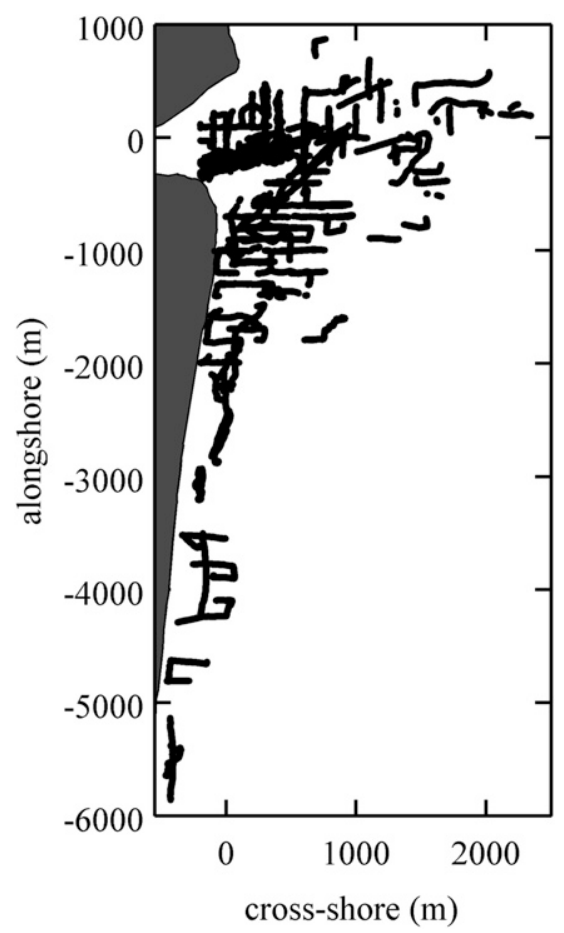

FIG. 6. Locations of collocated in situ and hyperspectral data used for comparison in Fig. 7, with dark gray regions indicating land. 

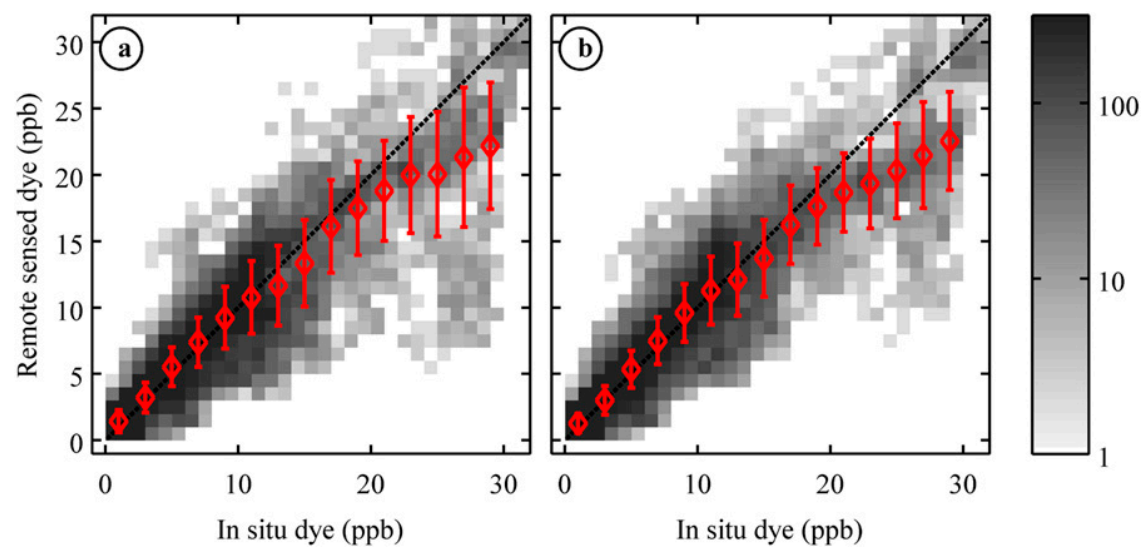

FIG. 7. (a) Hyperspectral dye estimate $\mathcal{D}_{H}$ (4) and (b) $\mathcal{D}_{\mathrm{H} 4}$ (5) vs in situ-measured dye concentration during RIVET, shown as binned means plus or minus one standard deviation (red curve) and the number of samples (logarithmic gray background, see legend). All data points shown are used in fitting (4) and (5).

The hyperspectral system linear fit (4) dye concentration errors are $10 \%-30 \%$ less than the multispectral system linear fit (3), which may be due to different water properties at IB09 and RIVET or may result from the calibrated radiance measurements and better spatial accuracy of the hyperspectral system. The hyperspectral dye concentration fits (4) and (5) can be applied to other calibrated radiance data in similar coastal waters, while the multispectral fit (3) uses uncalibrated images and can be applied only to the same camera system. However, calibration of a multispectral system (not performed here) is possible with a target of known reflectance in the image.

The four-band hyperspectral dye estimate $\mathcal{D}_{\mathrm{H} 4}(5)$ corrects for changes in background ocean color and reduces errors by $15 \%-25 \%$ over the two-band hyperspectral estimate (4), but it does not reduce the bias at high dye concentrations. The changes in background ocean color appear to be caused by suspended sediment in the water column and are consistent with previous work where red and NIR reflectance increase with suspended sediment concentrations (e.g., Nechad et al. 2010). However, no measurements of suspended sediment are available to test this directly. In water with high $R_{\mathrm{NIR}}$, the two-band $\mathcal{D}_{H}$ underpredicts the in situ measurement. Similarly, the multispectral $\mathcal{D}_{M}$ significantly underpredicts the in situ measurements in large rip currents, which have high sediment concentrations.

The hyperspectral dye concentration fits (4) and (5) are applicable to calibrated images using the same wavelength bands in similar optically deep coastal waters. For dye concentrations below $20 \mathrm{ppb}$, the nearly linear relationship between $R$ and $D$ for both calibrated hyperspectral and uncalibrated multispectral images will allow for tracer dispersion estimates from the second spatial moments of the tracer field without ground truth by in situ dye measurements. The second moment

$$
\sigma_{x x}^{2}=\frac{\int(x-\bar{x})^{2} D d x}{\int D d x},
$$

where $x$ is a spatial coordinate and the integrals are taken over the spatial domain containing the dye field, depends on relative concentration and not absolute concentration. Thus, an uncalibrated $\mathcal{D}=R+\beta$ can be substituted for $D$ in (6) when the relationship between $D$ and $R$ is linear, and the constant $\beta$ is chosen so that $\mathcal{D}=0$ in a region of the image that is known to be dye free.

\section{Summary}

Two simple methods for estimating near-surface dye concentration in turbid coastal waters were explored, with the goal of producing tracer maps suitable for studying tracer dispersion and lateral tracer structure. The ratio of imaged radiances (or pixel brightness) near the emission and excitation wavelengths of Rhodamine WT is fit as a linear function to the in situ dye observations with good agreement $\left(r^{2}=0.71\right.$, and 0.85$)$. The ratio of near-infrared to blue-green radiances is used to improve the hyperspectral dye estimate $\left(r^{2}=0.88\right)$ and accounts for variations in background ocean color. The methods were applied over varying light conditions without modeling the radiative transfer function. The roughly linear relationship between dye concentration and the ratio $R$ allows for relative concentration maps 

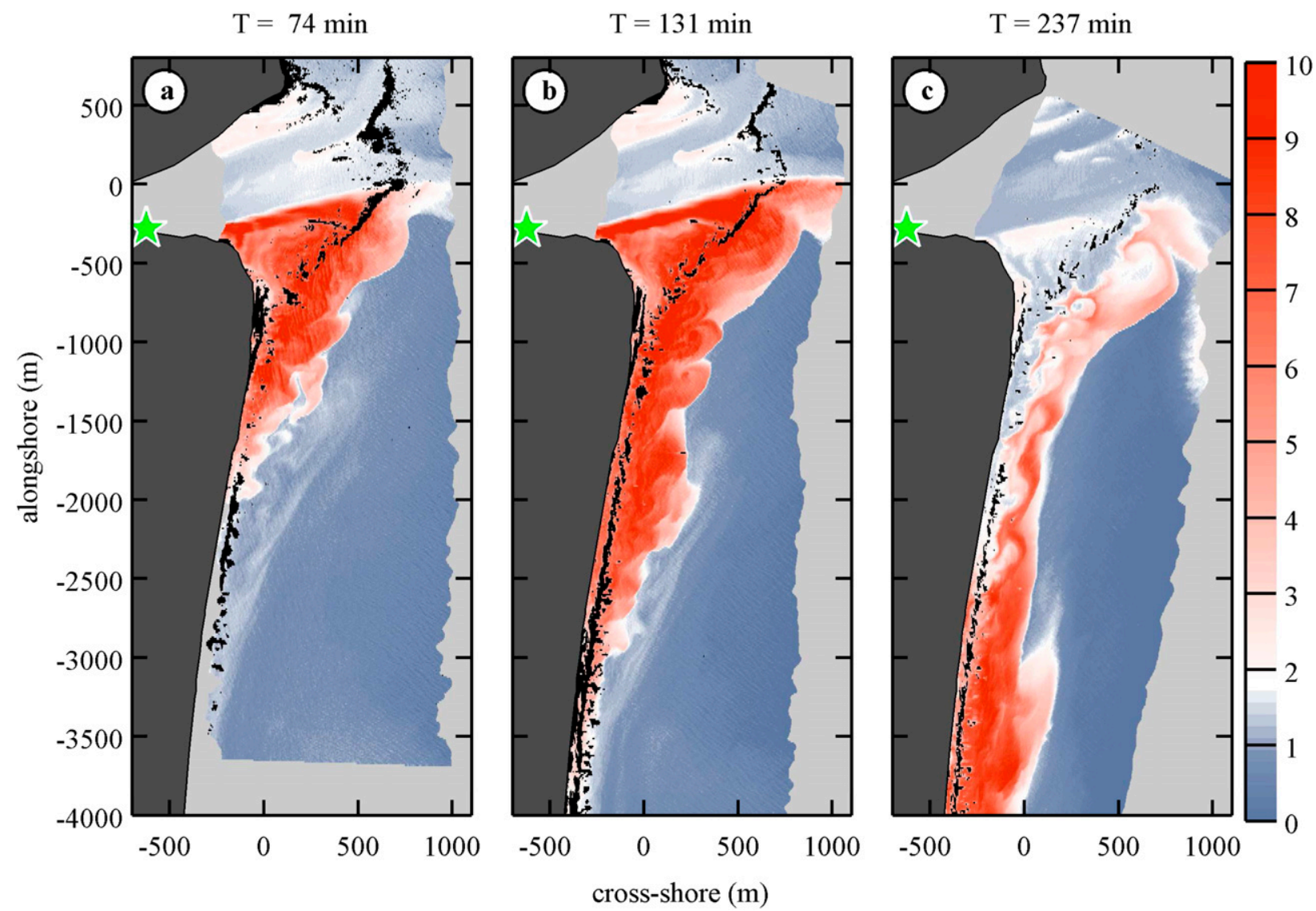

FIG. 8. Hyperspectral estimated dye concentrations (ppb; see legend) on 7 May 2012 during RIVET. Dye was released continuously just inside the inlet (green star symbol) from $T=0$ to $139 \mathrm{~min}$, and image times are noted in the panel titles. Dark gray regions indicate land, light gray regions indicate water outside the imaged area, and black regions indicate foam from breaking waves.

suitable for studying tracer dispersion using uncalibrated pixel brightness and without calibration by in situ measurements, for dye concentration $<20 \mathrm{ppb}$.

Acknowledgments. We thank Bill Boyd, Brian Woodward, Dennis Darnel, Kent Smith, Rob Grenzeback, Andrew Gale, Zoe Dagan, Kai Hally-Rosendahl, Megan Rippy, Marissa Yates, Melissa Omand, Nick Statom, and Brad Busch for their assistance in the lab, field, and air. We thank the lifeguards and staff at Imperial Beach, and the staff at the YMCA Surf Camp at Imperial Beach for their cooperation. We thank ONR and NSF for funding this work.

\section{APPENDIX}

\section{Nonlinearity of the radiance ratio $R$}

The ratio (1) of radiances at the dye emission $\left(\lambda_{\mathrm{em}}\right)$ and excitation $\left(\lambda_{\text {ex }}\right)$ wavelengths can be decomposed into the elastic radiance contribution $(L)$ and the contribution from inelastic scattering, for example, fluorescence $\left(L_{f}\right)$ :

$R=\frac{L\left(\lambda_{\mathrm{em}}\right)+L_{f}\left(\lambda_{\mathrm{em}}\right)}{L\left(\lambda_{\mathrm{ex}}\right)}=\frac{L\left(\lambda_{\mathrm{em}}\right)}{L\left(\lambda_{\mathrm{ex}}\right)}+\frac{L_{f}\left(\lambda_{\mathrm{em}}\right)}{L\left(\lambda_{\mathrm{ex}}\right)}$.

The first term, the elastic radiance ratio, $L\left(\lambda_{\mathrm{em}}\right) / L\left(\lambda_{\mathrm{ex}}\right)$, is the $O(1)$ ratio of the excitation and emission radiances in dye-free water [e.g., varies from 0.4 to 1.23 in the synthetic dataset of the International Ocean Colour Coordinating Group (IOCCG) (Lee 2006)]. The calibrated hyperspectral dye concentration fit (4) is consistent with this range of values, where $R=10.7 / 14.2=0.75$ when $\mathcal{D}_{H}=0$. The elastic term varies with particle concentration and is consistent with the varying intercept in (5), although this variation is small in the observed data.

The inelastic component of the radiance observed just above the surface $\left(z=0^{+}\right)$from the water column just below the surface $\left(z=0^{-}\right)$can be expressed as follows (see appendix in Behrenfeld et al. 2009): 


$$
L_{f}\left(0^{+}, \lambda_{\mathrm{em}}\right)=0.54 C \frac{\phi \int a_{\mathrm{dye}}\left(\lambda_{\mathrm{ex}}\right) E_{0}\left(0^{-}, \lambda_{\mathrm{ex}}\right) d \lambda_{\mathrm{ex}}}{K\left(\lambda_{\mathrm{ex}}\right)+k\left(\lambda_{\mathrm{em}}\right)}
$$

where $a_{\text {dye }}$ is the absorption coefficient of dye-laden water (varies with dye concentration) at the excitation wavelength, $E_{0}\left(\lambda_{\text {ex }}\right)$ is the downwelling scalar irradiance at the excitation wavelength, $K$ is the diffuse attenuation of the downwelling scalar irradiance at the excitation wavelength, $k$ is the diffuse attenuation of the isotropic fluoresced light, $\phi$ is the quantum yield of fluorescence (e.g., photon fluoresced per photon absorbed), the factor of 0.54 includes transmission (0.97) and the effects of refraction $\left(1.34^{-2}=0.56\right)$ across the interface (a total factor of $0.97 \times 0.56=$ 0.54 ), and $C$ is the inverse magnitude of the wavelength window over which the dye absorption $\left(a_{\text {dye }}\right)$ is excited $\left(\mathrm{m}^{-1}\right)$. The dye absorption $a_{\text {dye }}$ is a linear function of concentration $D$.

On the other hand, the ratio of elastic radiance to scalar irradiance can be written (Gordon et al. 1988) as

$$
\frac{L\left(\lambda_{\mathrm{ex}}\right)}{E_{0}\left(\lambda_{\mathrm{ex}}\right)}=C_{2} \frac{b_{b}\left(\lambda_{\mathrm{ex}}\right)}{a\left(\lambda_{\mathrm{ex}}\right)+b_{b}\left(\lambda_{\mathrm{ex}}\right)},
$$

where $C_{2}=0.10 / 0.87=0.11$, assuming downwelling irradiance to be $\approx 0.87$ times scalar irradiance (e.g., Westberry and Siegel 2003; Morel and Gentili 2004), $a$ is the water absorption coefficient, and $b_{b}$ is the backscatter coefficient. For highly scattering waters, this constant is likely smaller (e.g., Kirk 1994). This linear relation works at low to moderate turbidities.

The diffuse attenuation coefficient is further approximated as the sum of absorption and backscattering divided by the averaged cosine of the light field (e.g., Kirk 1994). Assuming the downwelling light has an average cosine of 0.8 (Kirk 1994) and the upward emitted light has an average cosine of 0.5 (isotropic),

$$
\begin{aligned}
& L_{f}\left(\lambda_{\mathrm{em}}\right) \\
& \quad=0.54 \phi \frac{\left\langle a_{\mathrm{dye}}\left(\lambda_{\mathrm{ex}}\right)\right\rangle\left\langle E_{0}\left(\lambda_{\mathrm{ex}}\right)\right\rangle}{1.25\left[a\left(\lambda_{\mathrm{ex}}\right)+b_{b}\left(\lambda_{\mathrm{ex}}\right)\right]+2\left[a\left(\lambda_{\mathrm{em}}\right)+b_{b}\left(\lambda_{\mathrm{em}}\right)\right]},
\end{aligned}
$$

where the integral divided by the excitation window $C^{-1}$ is replaced by the product of an average excitation absorption and an average excitation irradiance (which is spectrally flat).

Combining (A3) and (A4),

$$
\begin{aligned}
\frac{L_{f}\left(\lambda_{\mathrm{em}}\right)}{L\left(\lambda_{\mathrm{ex}}\right)}= & 5 \phi \frac{a\left(\lambda_{\mathrm{ex}}\right)+b_{b}\left(\lambda_{\mathrm{ex}}\right)}{b_{b}\left(\lambda_{\mathrm{ex}}\right)} \\
& \times \frac{\left\langle a_{\mathrm{dye}}\left(\lambda_{\mathrm{ex}}\right)\right\rangle}{1.25\left[a\left(\lambda_{\mathrm{ex}}\right)+b_{b}\left(\lambda_{\mathrm{ex}}\right)\right]+2\left[a\left(\lambda_{\mathrm{em}}\right)+b_{b}\left(\lambda_{\mathrm{em}}\right)\right]}
\end{aligned}
$$

and

$$
=\frac{5 \phi}{b_{b}\left(\lambda_{\mathrm{ex}}\right)} \frac{\left\langle a_{\mathrm{dye}}\left(\lambda_{\mathrm{ex}}\right)\right\rangle}{\left\{1.25+2\left[\frac{a\left(\lambda_{\mathrm{em}}\right)+b_{b}\left(\lambda_{\mathrm{em}}\right)}{a\left(\lambda_{\mathrm{ex}}\right)+b_{b}\left(\lambda_{\mathrm{ex}}\right)}\right]\right\}} .
$$

If the dyed water mass is advected with little change in its inherent optical properties (except for the dilution of the dye), then this ratio will be close to linearly proportional to the dye concentration with the proportionality constant proportional to the fluorescence quantum yield and inversely proportional to the backscattering coefficient (which is dominated by particles). The dye concentration, if it is high enough, could modify the ratio in the denominator, resulting in nonlinear behavior (the direction of that behavior depends on the value of this ratio at low dye concentrations).

The ratio of the radiance at the fluorescence wavelength to the excitation wavelength following an advected water mass of constant optical properties (other than the dilution of the dye) should

- Depend linearly on the dye concentration, for low concentrations (relative to water absorption, e.g., $0.13 \mathrm{~m}^{-1}$ at the emission wavelength),

- Have an $O(1)$ offset from the term dependent on dye concentration due to ambient reflectance [e.g., the nonzero intercept in (4) and (5)], and

- Exhibit nonlinear behavior at high dye concentration, and the nonlinearity depends on the ratio $\left[a\left(\lambda_{\mathrm{em}}\right)+\right.$ $\left.b_{b}\left(\lambda_{\mathrm{em}}\right)\right] /\left[a\left(\lambda_{\mathrm{ex}}\right)+b_{b}\left(\lambda_{\mathrm{ex}}\right)\right]$ in dye-free water.

\section{REFERENCES}

Behrenfeld, M. J., and Coauthors, 2009: Satellite-detected fluorescence reveals global physiology of ocean phytoplankton. Biogeosciences, 6, 779-794, doi:10.5194/bg-6-779-2009.

Bogucki, D. J., B. H. Jones, and M.-E. Carr, 2005: Remote measurements of horizontal eddy diffusivity. J. Atmos. Oceanic Technol., 22, 1373-1380, doi:10.1175/JTECH1794.1.

Bouguet, J.-Y., cited 2013: Camera calibration toolbox for MATLAB. California Institute of Technology. [Available online at http:// www.vision.caltech.edu/bouguetj/calib_doc/.]

Clark, D. B., F. Feddersen, M. M. Omand, and R. T. Guza, 2009: Measuring fluorescent dye in the bubbly and sediment-laden surfzone. Water Air Soil Pollut., 204, 103-115, doi:10.1007/ s11270-009-0030-z. 
and R. T. Guza, 2010: Cross-shore surfzone tracer dispersion in an alongshore current. J. Geophys. Res., 115, C10035, doi:10.1029/2009JC005683.

Csanady, G. T., 1963: Turbulent diffusion in Lake Huron. J. Fluid Mech., 17, 360-384, doi:10.1017/ S0022112063001403.

Feddersen, F., 2012: Scaling surf zone turbulence. Geophys. Res. Lett., 39, L18613, doi:10.1029/2012GL052970.

Fong, D. A., and M. T. Stacey, 2003: Horizontal dispersion of a near-bed coastal plume. J. Fluid Mech., 489, 239-267, doi:10.1017/S002211200300510X.

Gordon, H. R., O. B. Brown, R. H. Evans, J. W. Brown, R. C. Smith, K. S. Baker, and D. K. Clark, 1988: A semianalytic radiance model of ocean color. J. Geophys. Res., 93, 10909 10 924, doi:10.1029/JD093iD09p10909.

Grant, S. B., J. H. Kim, B. H. Jones, S. A. Jenkins, J. Wasyl, and C. Cudaback, 2005: Surf zone entrainment, along-shore transport, and human health implications of pollution from tidal outlets. J. Geophys. Res., 110, C10025, doi:10.1029/ 2004JC002401.

Harris, T. F. W., J. M. Jordaan, W. R. McMurray, C. J. Verwey, and F. P. Anderson, 1963: Mixing in the surf zone. Int. J. Air Water Pollut., 7, 649-667.

Holland, K. T., R. A. Holman, T. C. Lippmann, J. Stanley, and N. Plant, 1997: Practical use of video imagery in nearshore oceanographic field studies. IEEE J. Oceanic Eng., 22, 8192, doi:10.1109/48.557542.

Kirk, J. T. O., 1994: Light and Photosynthesis in Aquatic Ecosystems. 2nd ed. Cambridge University Press, 528 pp.

Kleiss, J. M., 2009: Airborne observations of the kinematics and statistics of breaking waves. Ph.D. thesis, Scripps Institution of Oceanography, University of California, San Diego, 218 pp.

Lee, Z., Ed., 2006: Remote sensing of inherent optical properties: Fundamentals, tests of algorithms, and applications. IOCCG Rep. 5, 126 pp.
Morel, A., and B. Gentili, 2004: Radiation transport within oceanic (case 1) waters. J. Geophys. Res., 109, C06008, doi:10.1029/ 2003JC002259.

Nechad, B., K. Ruddick, and Y. Park, 2010: Calibration and validation of a generic multisensor algorithm for mapping of total suspended matter in turbid waters. Remote Sens. Environ., 114, 854-866, doi:10.1016/j.rse.2009.11.022.

Okubo, A., 1971: Oceanic diffusion diagrams. Deep-Sea Res. Oceanogr. Abstr., 18, 789-802, doi:10.1016/0011-7471(71)90046-5.

Pope, R. M., and E. S. Fry, 1997: Absorption spectrum (380$700 \mathrm{~nm}$ ) of pure water. II. Integrating cavity measurements. Appl. Opt., 36, 8710-8723, doi:10.1364/AO.36.008710.

Pritchard, D. W., and J. H. Carpenter, 1960: Measurements of turbulent diffusion in estuarine and inshore waters. Bull. Int. Assoc. Sci. Hydrol., 5, 37-50, doi:10.1080/02626666009493189.

Rippy, M. A., P. J. S. Franks, F. Feddersen, R. T. Guza, and J. A. Warrick, 2013: Beach nourishment impacts on bacteriological water quality and phytoplankton bloom dynamics. Environ. Sci. Technol., 47, 6146-6154, doi:10.1021/es400572k.

Smart, P. L., and I. M. S. Laidlaw, 1977: An evaluation of some fluorescent dyes for water tracing. Water Resour. Res., 13, 1533, doi:10.1029/WR013i001p00015.

Spitzer, D., and M. R. Wernand, 1983: Multispectral remotesensing of fluorescent tracers: Theory and experiments. Oceanol. Acta, 6, 201-210.

Sundermeyer, M. A., E. A. Terray, J. R. Ledwell, A. G. Cunningham, P. E. LaRocque, J. Banic, and W. J. Lillycrop, 2007: Threedimensional mapping of fluorescent dye using a scanning, depthresolving airborne lidar. J. Atmos. Oceanic Technol., 24, 1050-1065, doi:10.1175/JTECH2027.1.

Viriot, M. L., and J. C. Andre, 1989: Fluorescent dyes: A search for new tracers for hydrology. Analusis, 17, 97-111.

Westberry, T., and D. Siegel, 2003: Phytoplankton natural fluorescence in the Sargasso Sea: Prediction of primary production and eddy induced nutrient fluxes. Deep-Sea Res. I, 50, 417-434, doi:10.1016/S0967-0637(03)00019-0. 